\title{
Using DTSA-II Tools for Electron-Excited X-ray Microanalysis of Thin Films
}

\author{
Dale Newbury ${ }^{1}$, Nicholas Ritchie ${ }^{2}$, Charles Tarrio ${ }^{2}$ and Robert Berg ${ }^{2}$ \\ ${ }^{1}$ National Institute of Standards and Technology, Gaithersburg, Maryland, United States, ${ }^{2}$ National Institute of \\ Standards \& Technology, Gaithersburg, Maryland, United States
}

Quantitative electron-excited X-ray microanalysis with energy dispersive spectrometry (EDS) [1] was used in support of an NIST study of the mechanisms of degradation of metal foil filters subjected to intense ultraviolet radiation in space-based solar instrumentation. To simulate the service conditions, aluminum and zirconium filters were exposed to controlled doses of focused UV radiation in the NIST Synchrotron Ultraviolet Research Facility under selected atmospheres, e.g., toluene, to represent the organic vapors outgassing from the spacecraft that could subsequently react with the filter material, or water, which can oxidize the metals. The resulting deposits induced by the focused UV beam were revealed with scanning electron microscopy (SEM) using the Everhart-Thornley detector for secondary electron detection, as shown in the image inset in Figure 1. Measurements made on these regions and nearby background regions (i.e., not subject to UV) gave the EDS spectra shown in Figure 1. As a reference to "ground-truth" the foil measurements, an EDS spectrum measured on commercial Al foil is also included. With all spectra scaled to the $\mathrm{Al} \mathrm{K \alpha}, \beta$ peaks, the $\mathrm{O} \mathrm{K}$ peak intensity is highest in the spectrum measured at the center of the UV irradiated spot and lowest in the spot background, while the $\mathrm{O} \mathrm{K}$ intensity measured on the $\mathrm{Al}$ foil (which also includes low level peaks for $\mathrm{Mg}, \mathrm{Si}$, and $\mathrm{Fe}$ ) falls between. For all three measurement locations, the intensity of the $\mathrm{C} \mathrm{K}$ peak was similar. (Note that particular care was taken to minimize $\mathrm{C}$ contamination introduced in the SEM, including scanning a small raster rather than using a stationary point beam.) The EDS spectra were processed with NIST DTSA-II, a comprehensive software platform for quantifying and simulating electron-excited EDS spectra [2]. DTSA-II was used to determine k-ratios of the intensity of the measured O K and $\mathrm{C} \mathrm{K} \mathrm{X-ray} \mathrm{peaks} \mathrm{relative} \mathrm{to} \mathrm{intensities} \mathrm{measured} \mathrm{on} \mathrm{bulk} \mathrm{Al}_{2} \mathrm{O}_{3}$ and $\mathrm{C}$ by peak fitting using appropriate peak references from the standards. To interpret these measured k-ratios in terms of equivalent film thicknesses for the metal oxide and $\mathrm{C}$, the Monte Carlo electron trajectory simulation embedded in DTSA-II was employed to create working curves of calculated k-values vs. film thickness. In addition to bulk target simulation, the DTSA-II Monte Carlo includes several "set pieces" for specific specimen geometries, including a film on a substrate. The simulation reports the emitted X-ray intensity, corrected for specimen absorption, which is then compared to the emitted intensity calculated for bulk $\mathrm{Al}_{2} \mathrm{O}_{3}$ and $\mathrm{C}$ standards to form the respective k-ratios, giving the working curve as shown in Figure 2 for $\mathrm{Al}_{2} \mathrm{O}_{3}$ on $\mathrm{Al}$. Using the calculated working curves for $\mathrm{O}$ and $\mathrm{C}$ to find the equivalent thicknesses from the measured k-values gave the following results:

$\begin{array}{llc}\text { Location } & \mathrm{C}(\mathrm{nm}) & \mathrm{Al}_{2} \mathrm{O}_{3}(\mathrm{~nm}) \\ \text { Spot center } & 1.9 \mathrm{~nm} \pm 0.1 & 8.6 \pm 0.1 \\ \text { Spot background } & 2.3 \mathrm{~nm} \pm 0.1 & 3.5 \pm 0.1 \\ \text { Al foil } & 1.6 \mathrm{~nm} \pm 0.1 & 5.1 \pm 0.1\end{array}$

The thickness uncertainty range is based on the uncertainty in the measured k-ratio reported by DTSA-II. 


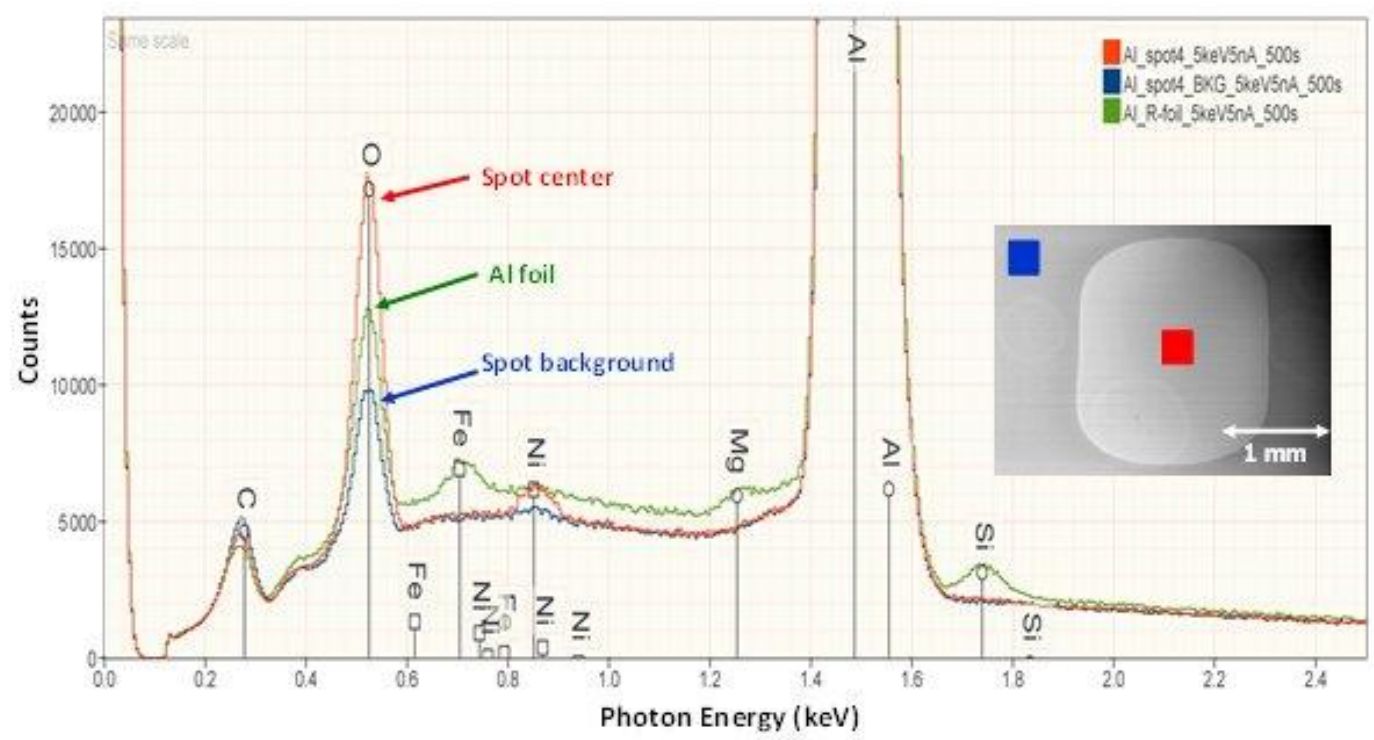

Figure 1. Figure 1. EDS Spectra measured with $\mathrm{E} 0=5 \mathrm{keV}$ at the spot center on the filter (red), the filter background (blue), and on a commercial $\mathrm{Al}$ foil, which also contains trace $\mathrm{Fe}, \mathrm{Mg}$, and $\mathrm{Si}$ (green).

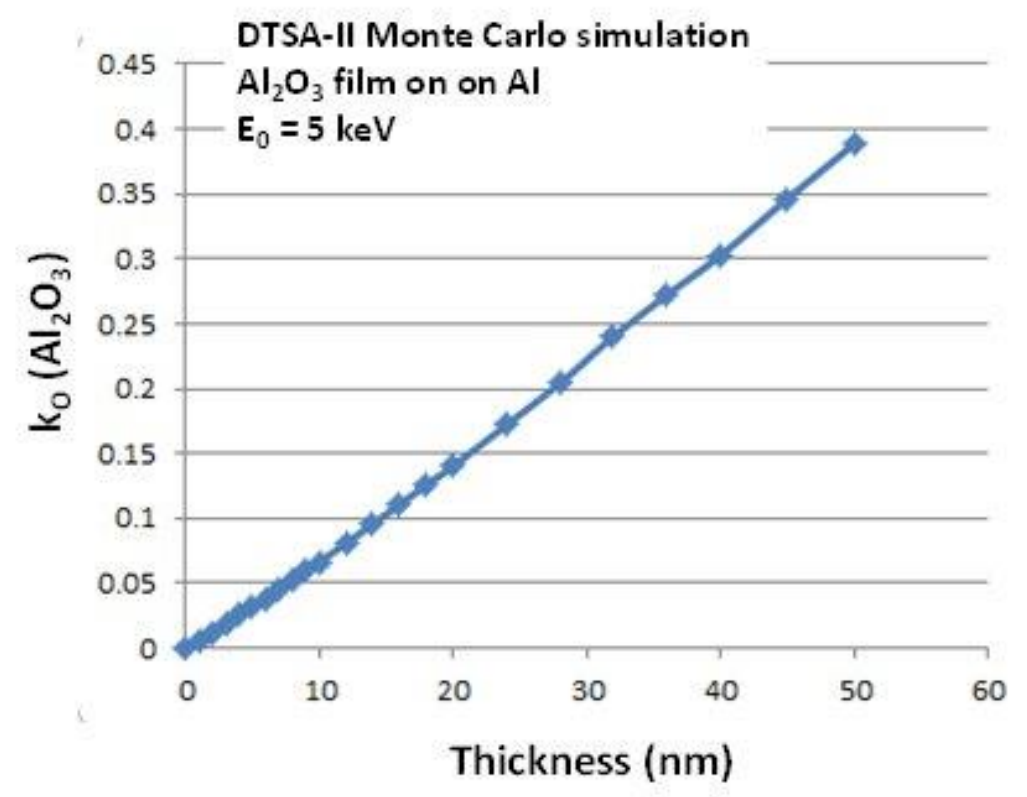

Figure 2. Figure 2. Working curve of $\mathrm{kO}$ vs film thickness for $\mathrm{Al} 2 \mathrm{O} 3$ on $\mathrm{Al}$ at $\mathrm{E} 0=5 \mathrm{keV}$; $\mathrm{Al} 2 \mathrm{O} 3$ as standard.

References

1. Goldstein, J., Newbury, D., Michael, J., Ritchie, N., Scott, J., and Joy, D., Scanning Electron Microscopy and X-ray Microanalysis, $4^{\text {th }}$ ed. (Springer, New York, 2018).

2. Ritchie, N. (2018). NIST DTSA-II software, including tutorials. Available for free at: http://www.cstl.nist.gov/div837/837.02/epq/dtsa2/index.html (retrieved December 21, 2020). 